\title{
Time to act now? Assessing the costs of delaying climate measures and benefits of early action
}

\author{
Michael Jakob • Gunnar Luderer • Jan Steckel • \\ Massimo Tavoni · Stephanie Monjon
}

Received: 19 May 2010 / Accepted: 17 May 2011 / Published online: 7 July 2011

(C) Springer Science+Business Media B.V. 2011

\begin{abstract}
This paper compares the results of the three state of the art climateenergy-economy models IMACLIM-R, ReMIND-R, and WITCH to assess the costs of climate change mitigation in scenarios in which the implementation of a global climate agreement is delayed or major emitters decide to participate in the agreement at a later stage only. We find that for stabilizing atmospheric GHG concentrations at 450 ppm $\mathrm{CO}_{2}$-only, postponing a global agreement to 2020 raises global mitigation costs by at least about half and a delay to 2030 renders ambitious climate targets infeasible to achieve. In the standard policy scenario-in which allocation of emission permits is aimed at equal per-capita levels in the year 2050-regions with above average emissions (such as the EU and the US alongside the rest of Annex-I countries) incur lower mitigation costs by taking early action, even if mitigation efforts in the rest of the world experience a delay. However, regions with low per-capita emissions which are net exporters of emission permits (such as India) can possibly benefit from higher future carbon prices resulting from a delay. We illustrate the economic mechanism behind these observations and analyze how (1) lock-in of carbon intensive infrastructure, (2) differences in global carbon prices, and (3) changes in reduction commitments resulting from delayed action influence mitigation costs.
\end{abstract}

\section{Introduction}

The accords that emerged as a result of recent UNFCCC negotiations in Copenhagen and Cancún recognize the scientific case for limiting global warming to below $2^{\circ} \mathrm{C}$

M. Jakob $(\bowtie) \cdot$ G. Luderer · J. Steckel

Potsdam Institute for Climate Impact Research, P.O. Box 601203, 14412 Potsdam, Germany

e-mail: jakob@pik-potsdam.de

M. Tavoni

Euro-Mediterranean Centre for Climate Change, Venice, Italy

S. Monjon

Centre International de Recherche sur l'Environnement et le Développement, Paris, France 
(cf. UNFCCC 2009). This is in line with the assertion that some of the most serious impacts of climate change could be averted by strong mitigation policy (Stern 2006). A large number of integrated assessment modeling studies suggest that ambitious climate measures can be implemented at global consumption losses not exceeding $2 \%$ (Stern 2006; Knopf et al. 2010). For instance, the model comparison by Luderer et al. (2011a) concludes that stabilizing atmospheric concentrations at $450 \mathrm{ppm} \mathrm{CO}_{2}$ only ${ }^{1}$ can be achieved at costs ranging from 0.1 to $1.4 \%$ of world GDP relative to the baseline, provided that full 'where' and 'when' flexibility (i.e. a global climate agreement that enters into force immediately) can be realized. However, ongoing negotiations for a global climate agreement show few signs of progress and it seems unlikely that a full agreement with globally binding targets to limit greenhouse gas emissions can be reached in the near future.

The question how to balance the environmental risks from too little or too late emission reductions against the economic risks from too much or too early abatement has received much attention in the run-up to the signature of the Kyoto protocol. Whereas some authors have argued that concentration pathways with higher nearterm emissions entail lower abatement costs (Wigley et al. 1996) and that a slow 'ramping-up' of mitigation efforts constitutes the most cost-efficient approach to slow down global warming (Nordhaus 1992; Nordhaus and Yang 1996), others have emphasized that inertias in the energy system increase the costs of deferring abatement to the future (Ha-Duong et al. 1997).

More recently, the debate on the implications of delayed action has reemerged as bottom-up approaches that suggest building a global carbon-market in a stepwise fashion if a global agreement fails to materialize have attracted considerable attention (see e.g. Flachsland et al. 2009). It has for instance been pointed out that if global annual emissions decline at a rate of $1 \%$ per year with the inception of a global agreement, delaying action by more than a decade would preclude stabilization of atmospheric $\mathrm{CO}_{2}$-concentrations below a doubling of pre-industrial levels (Mignone et al. 2008), and delayed action in a global climate regime has been addressed by several integrated assessment modeling studies (Keppo and Rao 2007; Edmonds et al. 2008; Bosetti et al. 2009; van Vliet et al. 2009; Richels et al. 2008). Two key insights from this literature can be summarized as follows: (1) the larger the nonparticipating regions' abatement potential and the longer the delay before they join a global climate agreement, the larger the increase in overall mitigation costs, and (2) the more ambitious the stabilization target, the larger the increase in mitigation costs caused by delayed participation. This is in line with the findings of the $22^{\text {nd }}$ Stanford Energy Modeling Forum, which employed ten leading integrated assessment models to generate scenarios in which BRIC countries start participating in the global effort to mitigate GHG emissions by 2030, and other non-Annex-I countries by 2050. Practically all models agree that delaying participation makes the most ambitious $450 \mathrm{ppm} \mathrm{CO}_{2}$-eq. stabilization target impossible to achieve and significantly raises mitigation costs for the intermediate $550 \mathrm{ppm} \mathrm{CO}_{2}$-eq. scenario (which more than double for some models), while impacts for $650 \mathrm{ppm} \mathrm{CO}_{2}$-eq. are much less severe (Clarke et al. 2009).

\footnotetext{
${ }^{1}$ This stabilization target corresponds to medium probabilities of keeping global temperature rise below $2^{\circ} \mathrm{C}$ (cf. Section 2.2.2).
} 
This study contributes to the existing literature on limited spatial and temporal flexibility of mitigation efforts by extending previous research on at least three accounts: first, it minimizes the role of uncertainty from model design by comparing the results from three state of the art energy-economy models IMACLIM-R, ReMIND$\mathrm{R}$, and WITCH, which were calibrated on harmonized socio-economic baseline assumptions. Second, it sheds some light on the regional distribution of mitigation costs in a rich set of delayed participation scenarios. Third, it thoroughly discusses how differences in model structures and assumptions impact on the numerical results, elaborates on the underlying economic intuition behind the observed model behavior, and performs a number of decompositions to gain a better understanding of the factors contributing to changes in mitigation costs.

This paper proceeds as follows: Section 2 describes the research design, including a brief description of the models, the model comparison framework, the baseline as well as the standard policy scenarios (in which full flexibility prevails). Section 3 presents the delayed action scenarios with restricted 'when' and 'where' flexibility on a global as well as regional level of aggregation, proposes a decomposition of changes in mitigation costs into changes of domestic abatement costs and changes of the carbon trade balance, and shows how these are related to the cumulative mitigation burden, marginal abatement costs, and the global carbon price. Section 4 concludes and discusses the policy implications of our results.

\section{Research design}

\subsection{The model comparison framework}

The economic analysis of climate change is concerned with parameter uncertainty (i.e. incomplete knowledge with regard to economic and technology parameters) as well as model uncertainty (i.e. having several plausible model structures). Carrying out model comparisons to deal with model uncertainty is an often used concept in climate economics (see e.g. Edenhofer et al. 2006). ${ }^{2}$ The three models employed in this model comparison represent very similar assumptions regarding underlying socioeconomic drivers of energy use and carbon emissions (i.e. population growth and world GDP, which were partly harmonized across models) but different visions of development and diffusion of new technologies as well as of economic mechanisms. ${ }^{3}$ IMACLIM-R (Sassi et al. 2010) is a recursive computable general equilibrium model in which agents behave semi-myopically with adaptative expectations, leading to sub-optimal investment decisions and unused production factors. Therefore, climate policies may be a means of remedying market failures. ReMIND-R (Leimbach et al. 2009) assumes inter-temporal optimization of global welfare with perfect foresight. The model includes a detailed description of energy carriers and conversion

\footnotetext{
${ }^{2}$ In this context, one should be aware that models are not designed to predict the future, but to generate plausible, self-consistent scenarios which can serve as tools for scientists and policymakers to explore the scope of possible developments, discuss the plausibility of underlying assumptions, and derive appropriate courses of action.

${ }^{3}$ Model designs and the associated assumptions are discussed in the synthesis paper (Luderer et al. 2011a).
} 
technologies as well as unrestricted inter-temporal trade relations and capital movements between regions. WITCH (Bosetti et al. 2006, 2007) is an optimization model accounting for the non-cooperative nature of international relations. It models the emergence of carbon-free backstop energy technologies as well as endogenous improvements in energy efficiency.

Comparing the results obtained for our benchmark stabilization with those of the delayed stabilization scenarios for these three models sheds some light on how different assumptions on technologies and economic dynamics translate into differences in mitigation costs. ${ }^{4}$ To derive meaningful conclusions on a regional scale, we aggregate the results from each model to six 'macro-regions', which are similar (albeit not identical) across models: The European Union (EU), the US (USA), Rest of Annex-I (R-AI), China (CHN), India (IND), and Rest of non-Annex-I (RNAI). The economic impacts of delays in climate policy are computed by comparing the macro-economic consumption paths that are obtained in the respective delayed action scenario with the one in the benchmark stabilization scenario (which features full 'where' and 'when' flexibility). The difference between these two trajectories determines the increase in mitigation costs due to delayed action. Based on standard economic theory, consumption losses can be considered an appropriate measure of the economic costs of climate policy. ${ }^{5}$ To make costs that arise in different points in time comparable, all costs are converted to net present values with a constant discount rate of $3 \% .{ }^{6}$ Damages caused by climate change are not part of this analysis ${ }^{7}$ and the model results do not constitute a cost-benefit-analysis but an assessment of how limited spatial and temporal flexibility influences the costs of stabilizing the atmospheric $\mathrm{CO}_{2}$ concentration at a certain pre-determined level.

\subsection{Benchmark mitigation costs}

\subsubsection{The reference scenario}

Our reference scenario depicts future developments in a world without climate mitigation measures. The three models employed use identical assumptions with regard to the development of global population and partially harmonized assumptions regarding economic activity: ${ }^{8}$ world population is assumed to keep growing, with a peak at 9.5 billion in the year 2070 and thereafter slightly decline to roughly 9 billion in 2100. GDP is projected to grow at rates close to historical values in industrial regions but more rapidly in newly industrializing and most (but not all) developing and least developed countries. The underlying storyline is that the US, Europe, and Japan are expected to remain the regions with the highest per capita

\footnotetext{
${ }^{4} \mathrm{~A}$ more detailed description of the model comparison framework can be found in Jakob et al. (2009b).

${ }^{5}$ To take into account inter-temporal consumption smoothing (i.e. shifting current consumption into the future by saving), we adjusted current consumption for REMIND-R by adding investments and the current account balance.

${ }^{6}$ Section 3.5 . includes a sensitivity study which assesses the robustness of the main results with respect to the discount rate.

7i.e. for WITCH - the only model that includes a damage function - damages were set to zero.

${ }^{8}$ The reference scenarios and their underlying storylines are described in Jakob et al. (2009a).
} 
(a) annual $\mathrm{CO}_{2}$ emissions

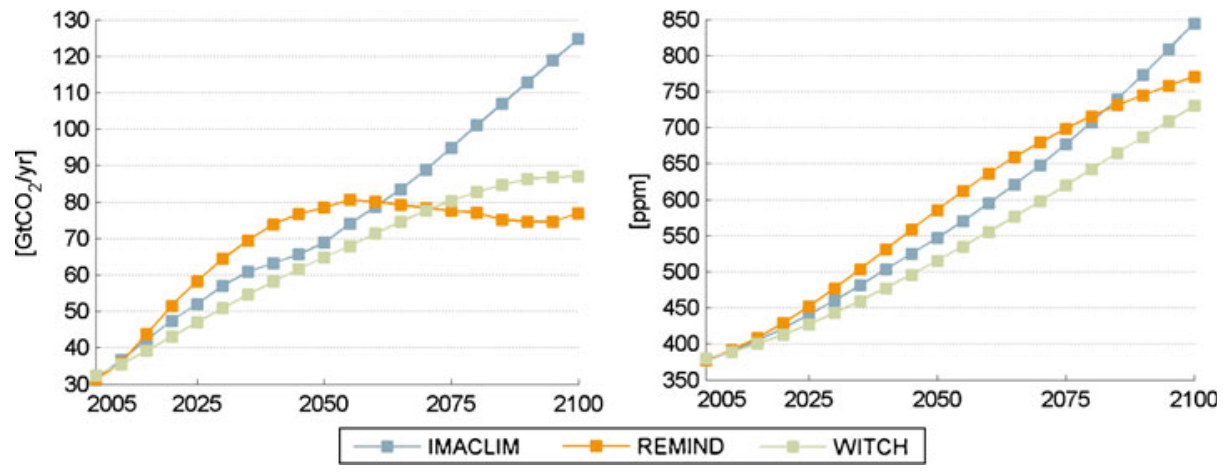

Fig. 1 Annual $\mathrm{CO}_{2}$ emissions (panel a) and atmospheric concentrations (panel b, $\mathrm{CO}_{2}$-only) in the reference scenario for IMACLIM-R, ReMIND-R, and WITCH

incomes at the end of the twenty-first century with other countries, especially China and India, closing the gap. Over the entire century, world GDP is assumed to increase on average between $2.1 \%$ (WITCH) and $2.4 \%$ (ReMIND-R) per year.

In all three models, energy demand is projected to rise throughout the whole of the twenty-first century, with increases of total primary energy consumption by factors between two-and-a-half (WITCH) and four (IMACLIM-R). Due to an energy mix that remains largely dominated by fossil fuel use, carbon emissions at the end of the century are several times their 2005 level. The IMACLIM-R baseline projects the highest $\mathrm{CO}_{2}$ emissions $\left(124 \mathrm{GtCO}_{2}\right.$ in 2100$)$ with a continuous increase beyond 2050 due to the availability of cheap coal as a substitute for oil, which prevents the penetration of non-fossil energies (Fig. 1a). In contrast, due to an energy demand $19 \%$ lower than the IMACLIM-R reference and a higher penetration of carbonfree energy (biomass and renewable), emissions in the ReMIND-R baseline decline after 2050 (after a high growth up to 2040) to reach $72 \mathrm{GtCO}_{2}$ in 2100 . The WITCH baseline reaches $86 \mathrm{GtCO}_{2}$ emissions in 2100, with low emission growth in the second half of the century. It is in aggregate close to the ReMIND-R scenario, with a lower energy intensity but a higher carbon intensity of its energy mix, compared to ReMIND-R and IMACLIM-R. The resulting carbon emissions give rise to atmospheric concentrations in the year 2100 between $730 \mathrm{ppm} \mathrm{CO}_{2}$ (WITCH), 750 ppm $\mathrm{CO}_{2}$ (ReMIND), and 840 ppm CO 2 (IMACLIM) (see Fig. 1b).

\subsubsection{The benchmark stabilization scenario with full spatial and temporal flexibility}

Our stabilization scenario considers a benchmark stabilization target of $450 \mathrm{ppm} \mathrm{CO}_{2}$ in the year 2100. ${ }^{9}$ Depending on assumptions about emissions of other greenhouse gases such as $\mathrm{CH}_{4}, \mathrm{~N}_{2} \mathrm{O}$ and fluorinated gases, this corresponds to overall $\mathrm{GHG}$

\footnotetext{
${ }^{9}$ IMACLIM-R allows for unlimited overshooting (i.e. exceeding the $450 \mathrm{ppm} \mathrm{CO}_{2}$ limit in any year prior to 2100) as long the constraint is met in the year 2100, while for WITCH overshoot was limited

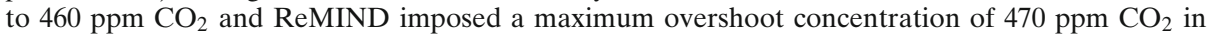
2070.
} 
(a) carbon prices (year 2005 USD)

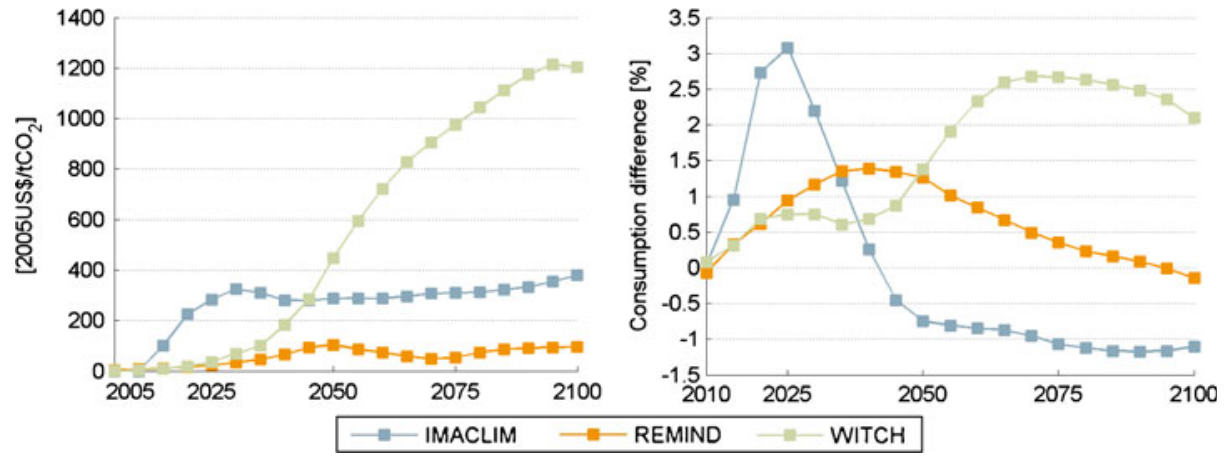

Fig. 2 Carbon prices (a) and consumption losses (b) in the benchmark 450 ppm stabilization scenario (with full spatial and temporal flexibility) for IMACLIM-R, ReMIND-R, and WITCH

concentrations of 500-550 ppm $\mathrm{CO}_{2}$-eq. (Fisher et al. 2007). According to the metric of cumulative emission budgets as proposed by Meinhausen et al. (2009)—which in our case lie between 1455 and $1533 \mathrm{Gt} \mathrm{CO}$ for the first half of the twenty-first century depending on the respective model-the mitigation effort envisaged by the stabilization scenarios results in medium probabilities (ranging from $42 \%$ to $49 \%$ ) of keeping global temperature rise below $2^{\circ} \mathrm{C}$.

Due to their structural differences and different representations of the energy system, the models project different economic effects of climate policy. The aggregated discounted mitigation costs in terms of consumption losses relative to the baseline ${ }^{10}$ accrue to $0.1 \%$ (IMACLIM-R), $0.7 \%$ (ReMIND-R), and $1.4 \%$ (WITCH). The size and temporal evolution of mitigation costs and the carbon price are shown in Fig. 2. The differences in model approaches are reflected in the structural differences of carbon price trajectories. In IMACLIM-R, under imperfect foresight very high carbon prices are required initially to create a sufficiently strong signal to overcome the technical inertias constraining the transition to a low-carbon energy system (Fig. 2a). These high prices result in very high transitional mitigation costs and welfare losses in the first 30 years of the modeled period (Fig. 2b). Once this transition is accomplished, IMACLIM-R projects negative mitigation costs due to additional technical change and the implementation of climate friendly transport infrastructure policy (two parameters that increase overall efficiency and help correcting the main source of sub-optimality in the baseline scenario i.e. the volatility of oil markets and the imperfect foresight of 'peak oil'). ReMIND-R and WITCH, by contrast, are perfect foresight intertemporal optimization models and therefore envisage a smoother development of the carbon price and almost steady (approximately exponential) increases until the middle of the twenty-first century. Endogenous technological progress (i.e. learning-by-doing) and non-linearities in the carbon cycle result in slower increases of the carbon price after 2050. WITCH exhibits significantly higher consumption losses compared to ReMIND-R, and long-term mitigation costs also

${ }^{10}$ We employ a discount rate of $3 \%$ over the period from 2005 to 2100. 
exceed those estimated by IMACLIM-R on the global scale. Due to the relatively more conservative assumptions concerning technology substitution within the energy sector, a larger share of the emissions reduction has to be delivered by curbing the economy's energy demand, resulting in a reduction of economic output. In ReMIND$\mathrm{R}$, the carbon price is projected to remain on a moderate level, as the model allows for more flexibility to bring about transformations of the energy system. Learning processes reduce the cost of low-carbon technologies, most notably renewables. The availability of cheap alternative energy sources reduces $\mathrm{CO}_{2}$ abatement costs and allows focusing the mitigation effort on decarbonization, while the reduction of energy demand plays a less important role.

The regional distribution of mitigation costs will be discussed in the next section in combination with the cost implication of delayed mitigation. With a global climate agreement the regional (but not the global) costs of mitigation measures critically depend on the burden sharing principle which determines the allocation of emission rights across regions. For the remainder of this paper, we presume that the Contraction and Convergence scheme (Meyer 2004), which envisages a smooth transition of emission shares from status quo (i.e. emissions in 2005) to equal per capita emissions in 2050, is adopted. This allocation scheme combines elements of grandfathering-allocation based on historic emissions-and equal per capita emissions and can be considered a compromise between a pure egalitarian regime and a grandfathering approach. ${ }^{11}$ Different degrees of participation to this scheme imply that non-committed countries are entitled to larger emissions, i.e. to emit as they would in the absence of any climate regulation.

\section{Effects of delayed participation}

Three distinct effects determine the impact of delayed mitigation efforts on abatement costs: first, regions that do not commit to reduce their emission in early years carry a lower share of the total mitigation effort undertaken globally over the century, which lowers their mitigation costs compared to the benchmark stabilization scenario. Second, acting myopically leads to a build-up of capital stock dedicated to carbon-intensive patterns of generating and using energy and increases future domestic mitigation costs. Third, myopic behavior and lock-in of carbon intensive energy infrastructure ${ }^{12}$ also affect global carbon prices that will be higher than in the benchmark stabilization scenario with full participation. As will be discussed in more detail below, this can have positive as well as negative effects on any region, depending on whether it is a net-seller or a net-buyer of emission permits (which, in turn, depends on its reduction commitment as well as the structure of its energy system). Depending on the relative magnitude of these effects, the welfare effects of delayed action for late movers are ambiguous.

\footnotetext{
${ }^{11}$ The role of different allocation rules on regional mitigation costs is discussed in Luderer et al. (2011b).

${ }^{12}$ Please note that in all three models energy infrastructure (such as generation capacity) is employed until the end of its life-time without the possibility of early retirement. Hence, the infrastructure in place constitutes a constraint for the stabilization target that can be achieved. See Davis et al. (2010) for a recent analysis of future $\mathrm{CO}_{2}$ emissions from existing energy infrastructure.
} 
Table 1 Description of delayed action scenarios

\begin{tabular}{ll}
\hline Scenario name & Scenario assumptions \\
\hline all2010 & $\begin{array}{l}\text { Global carbon market by 2010, regional allowance allocation by Contraction } \\
\text { and Convergence (2005 as base-year) }\end{array}$ \\
IC + CHN + IND & $\begin{array}{r}\text { All Annex-I countries plus China and India adopt cap-and-trade by 2010, } \\
\text { the rest of the world by } 2020 \\
\text { Participation of all Annex-I countries by 2010, with the rest of the world } \\
\text { IC only }\end{array}$ \\
EU only & $\begin{array}{l}\text { The European Union acts as an early mover, the rest of the world by } 2020 \\
\text { delay2020 }\end{array}$ \\
\hline
\end{tabular}

In the following we examine the aforementioned effects in detail. We start with a description of the delayed action scenarios, discuss their impact on global and regional mitigation costs, and then decompose changes in consumption losses into changes in domestic mitigation costs and changes in the carbon trade balance. The final sub-section presents the economic intuition behind the numerical results and illustrates the possible benefits of early action by analyzing the determinants of mitigation costs for the EU and the US.

\subsection{Stabilization scenarios with limited spatial and temporal flexibility}

The default policy scenarios presented earlier were based on the assumption of global collaborative action on climate change from 2010 on, ensuring full spatial and temporal flexibility of mitigation efforts. However, current negotiations on a post2012 climate regime indicate that substantial climate policy efforts may be lacking in some world regions in the near future. Against this background, we assess the costs of delaying the implementation of ambitious climate policy in some regions. The five scenarios which examine the most relevant configurations of commitments given the current negotiations (listed in Table 1) differ in their timing of introducing regional climate policy and represent plausible participation structures marked by different levels of political ambition. As a sensitivity check, we also examine a scenario with a longer delay, which assumes complete absence of climate policy until the year 2030.

In the early action scenarios the allocation of emission permits to regions that undertake climate policy during the years 2010 to 2020 equals their endowment in the 'all2010' scenario. International allowance trade can then occur between all regions with binding emission targets. Between 2010 and 2020, the regions that delay participation are assumed to behave myopically, i.e. they do not expect the introduction of carbon constraints and follow their business-as-usual development pathway. ${ }^{13}$ It is assumed that from 2020 on allowances are allocated according to the Contraction and Convergence rule with 2005 as the base year and 2050 as the convergence year. Therefore, regions' relative shares in global emissions remain

\footnotetext{
${ }^{13}$ This is a somehow extreme modeling assumption, as governments will build agreements on growing credibility of international negotiations and firms will start to respond to this expectation some time beforehand. However, it is hardly the case that anticipation of policy will go beyond 5 years, which is the time step used for ReMIND-R and WITCH in the comparison exercise, while for IMACLIM-R, expectations exclusively depend on past developments.
} 
Fig. 3 Global consumption losses $(\%)$ relative to the $\mathrm{BAU}$ scenario for the delayed participation scenarios and the 'all2010' scenario with full flexibility

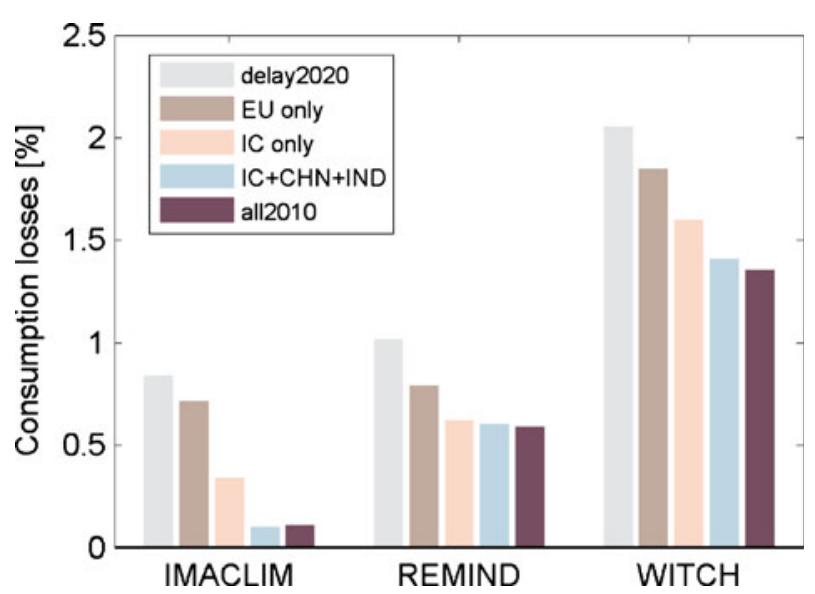

unchanged compared to the default $\mathrm{C} \& \mathrm{C}$ scenario. ${ }^{14}$ However, to compensate for the excess emissions produced during the period of delay, regional caps are contracted proportionally starting in 2020 . Thus, in the delay scenarios, the cumulative emissions across regions are shifted in favor of late movers who emit more than in the 'all2010' scenario with the world jointly making up for these excess emissions post-2020.

\subsection{Impact of delayed action on global mitigation costs}

Even with a global delay of mitigation action until 2020, our numerical results indicate that stabilization at $450 \mathrm{ppm} \mathrm{CO}_{2}$ by 2100 remains feasible, albeit at significantly higher costs than in the 'all2010' scenario. Discounted global consumption losses over the course of the twenty-first century increase from $1.4 \%$ to $2 \%$ in WITCH, from $0.6 \%$ to $1 \%$ in ReMIND-R and from $0.1 \%$ to $0.8 \%$ in IMACLIM-R (Fig. 3 ). In these simulations no constraints were put on the availability of technologies. Clearly, with a restricted set of technology options it would become increasingly difficult to achieve the $450 \mathrm{ppm}$ target if countries delay action on climate change. ${ }^{15}$

Including a larger number of key regions in the climate coalition of those taking early action by 2010 markedly decreases the global costs of stabilization. The participation of the Annex-I countries, as well as that of China and India is found to be critical for the magnitude of mitigation costs, with different accentuations depending on the respective model: all models project that early participation of Annex-I countries is particularly important, with global consumption losses in the 'IC only' scenario between 22\% (WITCH), 38\% (ReMIND-R), and 59\% (IMACLIM$\mathrm{R})$ lower than in the 'delay2020' scenario. In IMACLIM-R, the EU is found to play a lesser role for global mitigation costs, as consumption losses in the 'EU only' scenario

\footnotetext{
${ }^{14}$ Of course, alternative political outcomes in which late movers are rewarded with laxer reduction commitments are conceivable. However, game theoretic considerations related to the formation of coalition and incentives to contribute to the provision of a global public good are clearly beyond the scope of this paper.

${ }^{15}$ It should be noted that among the three models used in this study only ReMIND-R allows for the use of biomass in conjunction with CCS (which allows achieving negative emissions).
} 
are only slightly lower than in the 'delay2020' scenario, while pursuing climate policy in all Annex-I regions from 2010 on ('IC only') brings down global mitigation costs by more than half. For ReMIND-R and WITCH, on the other hand, the differences between the 'delay2020' and the 'EU only' scenarios are of comparable magnitude to those between the 'EU only' and the 'IC only' scenarios, respectively. This suggests that participation of both the EU as well as the US and the rest of Annex-I are important determinants of global mitigation costs. According to IMACLIM-R and WITCH early participation of China and India will also result in significant cost decreases; because of a higher degree of technological optimism that leads to lower carbon prices, this effect is less pronounced in ReMIND-R. None of the three models suggests that it is of particular importance for global mitigation costs to implement climate policies before 2020 in the rest of non-Annex-I (i.e. non-Annex-I excluding China and India). ${ }^{16}$

Finally, a delay of global climate policy until the year 2030 renders stabilization at 450 ppm $\mathrm{CO}_{2}$ infeasible ${ }^{17}$ in all models. ${ }^{18}$ This holds even in the case of ReMIND$\mathrm{R}$, which embodies the most optimistic assumptions on flexibility and availability of low-cost carbon-free technologies. This finding can be explained by the fact that (if no future reductions are anticipated) large amounts of carbon will already have been emitted to the atmosphere up to this date and substantial additional fossil energy conversion capacities will have been put into place. Due to the long-lived nature of the capital stock in the energy sector, the world would be committed to a large amount of further $\mathrm{CO}_{2}$ emissions after the onset of climate policy, which would make it impossible to keep atmospheric concentration below $450 \mathrm{ppm} \mathrm{CO}_{2}$.

\subsection{Impact of delayed action on the regional distribution of mitigation costs}

The changes of mitigation costs accruing to each region due to restricted spatial and temporal flexibility (compared to the 'all2010' scenario) are depicted in Fig. 4. We observe the (perhaps counter-intuitive) result that in all models, unilateral adoption of an emissions cap in 2010 by the EU (i.e. scenario 'EU only') results in lower mitigation costs for the EU, compared to the 'delay2020' scenario. Remarkably, this effect holds both for the forward looking models WITCH and ReMIND-R in which

\footnotetext{
${ }^{16}$ Global mitigation costs in IMACLIM-R are in fact projected to be lower if action in the rest of non-Annex-I is delayed. This result comes from the larger consumption losses of EU, US, RAI and CHN in the scenario 'all2010' than in the scenario 'IC+CHN+IND' which over-compensate the larger gains of IND and RNAI (see Fig. 4). These differences are explained by a higher carbon price during the period 2010-2020 due to the absence of the RNAI in the global carbon market.

${ }^{17}$ For the purpose of this paper, feasibility is defined as a model's ability to find a numerical solution (i.e. achieve convergence of the solution algorithm).

${ }^{18}$ For ReMIND-R, the only model for which the option of generating negative emissions by combining biomass with CCS (BECCS) is available, stabilization at $450 \mathrm{ppm} \mathrm{CO}_{2}$ in 2100 is only feasible if the constraint on overshooting is removed. In this case, the $\mathrm{CO}_{2}$ concentration reaches $535 \mathrm{ppm}$ in 2055 before declining. Constraining overshooting at $520 \mathrm{ppm} \mathrm{CO}_{2}$ or lower makes stabilization at $450 \mathrm{ppm} \mathrm{CO}_{2}$ in 2100 infeasible.
} 
(a) $\mathbf{E U}$

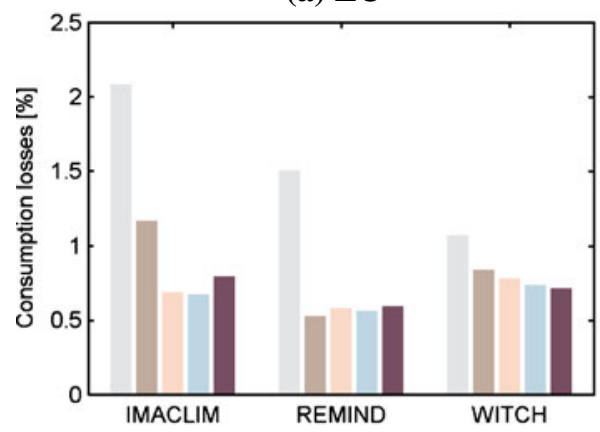

(c) RAI

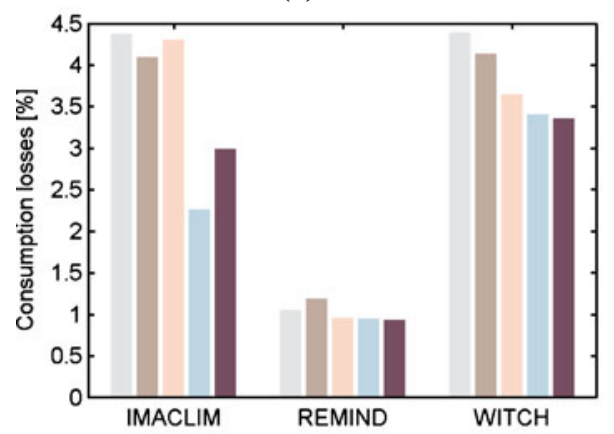

(e) IND

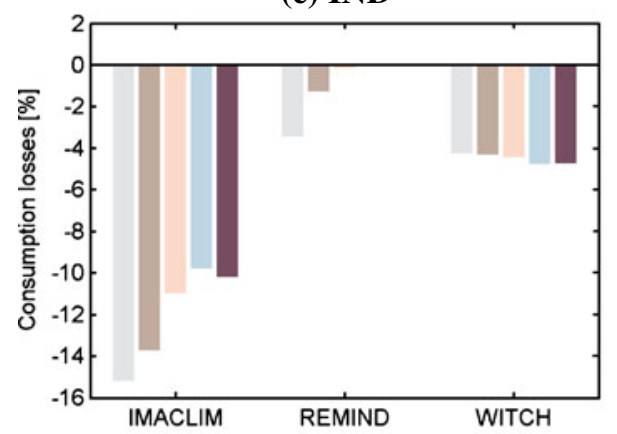

delay2020 EU only (b) US

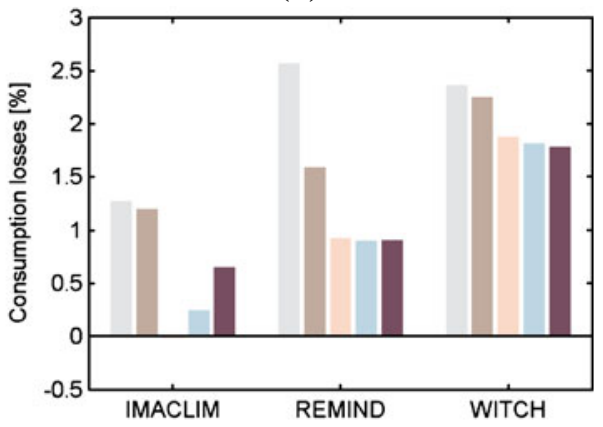

(d) $\mathrm{CHN}$

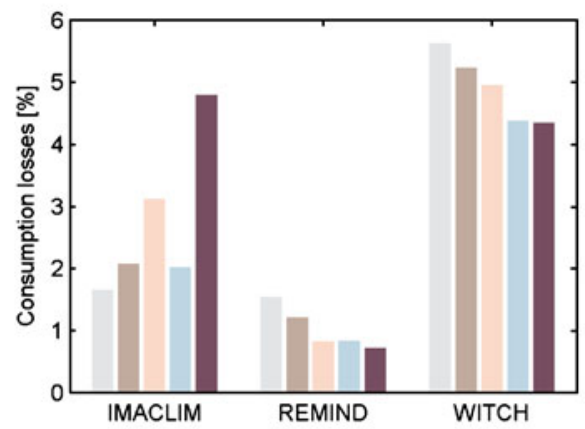

(f) RNAI

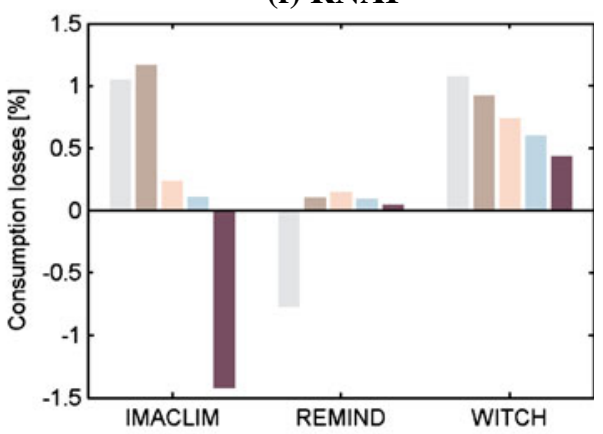

IC only IC+CHN+IND $\quad$ all2010

Fig. 4 a-f Consumption losses (\%) for the delayed action scenarios as well as the 'all2010' scenario relative to the BAU scenario, disaggregated by world regions. Please note different scales

the EU strongly benefits from the anticipation of future climate policy constraints as well as the recursive model IMACLIM-R, where the EU's energy system benefits from being pushed into a more efficient mode of operation early. This indicates that even if the other regions do not participate immediately there is an incentive 
for the EU to act, with early action decreasing mitigation costs from $2.1 \%$ to $1.2 \%$ in IMACLIM-R, from $1.5 \%$ to $0.5 \%$ in ReMIND-R, and from $1.1 \%$ to $0.8 \%$ in WITCH. ${ }^{19}$ Similarly, mitigation costs for the US decrease if they join a climate policy regime alongside other Annex-I countries by 2010 compared to the case where only the European Union adopts limits on carbon emissions. For the US, IMACLIM-R estimates that early action decreases mitigation costs from $1.2 \%$ to a slightly negative value (i.e. net gains compared to business-as-usual); ReMIND-R indicates a drop from $1.5 \%$ to $0.8 \%$, and WITCH from $2.2 \%$ to $1.8 \%$.

According to IMACLIM-R and WITCH, if all Annex-I countries are committed to climate policy China will increase its welfare if it-together with Indiaparticipates in the reduction effort early on, while ReMIND-R suggests that the early and the delayed action scenarios result in very similar levels of consumption for China. As IMACLIM-R presumes suboptimal technology choices in the Chinese energy sector, a higher carbon price proves in fact beneficial in internalizing part of these non-environmental market failures and results in smaller consumption losses for China in all delay scenarios compared to the scenario with full flexibility. For India, by contrast, the effect of early participation of China and India in a global carbon market is expected to be roughly neutral. Countries with low per-capita emissions which are net-sellers of emission permits can potentially reap benefits if action in other regions is delayed because of a higher carbon price and the associated extra revenues from emissions trading. IMACLIM-R and ReMIND-R suggest that this might indeed be the case for India, as in most delay scenarios India's consumption losses are smaller than in the 'all2010' scenario. Finally, the results for the rest of non-Annex-I countries appear to contain little conclusive evidence at this level of disaggregation, an issue that will be addressed in more detail in the next section.

Hence, we conclude that for the majority of regions, even though appealing from the short term perspective, delaying action on climate policy does not turn out to decrease long run consumption losses. Even though late movers have the advantage of laxer reduction commitments regarding their cumulative emissions over the century ${ }^{20}$ this effect is countered by increased future mitigation costs arising from the build-up of long-lived carbon-intensive infrastructure. By contrast, early action provides more leeway for adjustments of the energy system and opportunities to utilize the least expensive mitigation options (i.e. 'picking the low-hanging fruit'). As avoiding lock-in effects and faster learning in wind and solar technology (plus investments in energy $\mathrm{R} \& \mathrm{D}$ in WITCH) bring down costs, emission reductions beyond 2020 become less expensive. For this reason, early adoption of climate policy by a subset of regions is projected to prove beneficial by the time a global climate policy is incepted, not only for regions which can take a 'free-ride' (as they will be bound to less stringent reduction commitments later on), but even for the early adopters themselves.

\footnotetext{
${ }^{19}$ Short term losses and competitiveness issues associated to energy intensive sectors are compensated by medium term gains, hence these results hold as we keep a medium term horizon in evaluating losses.

${ }^{20}$ i.e. the additional abatement to be performed is divided between all regions and the increase of the burden for late movers is less than the abatement foregone in early years.
} 
3.4 Decomposing regional mitigation costs

Total consumption losses for each region are determined by the costs of mitigating domestic carbon emissions minus net exports of emission permits (i.e. the carbon trade balance, defined as the net monetary value of emissions permits sales on the global carbon market). Regions that meet part of their reduction commitments by importing emission permits face a negative carbon trade balance, which raises their total consumption losses beyond the costs incurred for domestic abatement. To gain a deeper understanding with regard to the effects of delayed action, we decompose changes in regional consumption losses into changes of domestic mitigation costs and changes of the carbon trade balance relative to the 'all2010' scenario (see also Luderer et al. 2011b):

$$
\begin{aligned}
N P V\left(C L_{i}^{\text {delay }}-C L_{i}^{\text {all2010 }}\right)= & \operatorname{NPV}\left(D M C_{i}^{\text {delay }}-D M C_{i}^{\text {all2010 }}\right) \\
& -N P V\left(C T B_{i}^{\text {delay }}-C T B_{i}^{\text {all2010 }}\right)
\end{aligned}
$$

$N P V$

$C L_{i}^{\text {delay }}, C L_{i}^{\text {all } 2010}$

$D M C_{i}^{\text {delay }}, D M C_{i}^{\text {all } 2010}$

$C T B_{i}^{\text {delay }}, C T B_{i}^{\text {all2010 }}$ net present value

consumption losses for region $\mathrm{i}$ for the delay and the 'all2010' scenarios, respectively

domestic mitigation costs for region i for the delay and the 'all2010' scenarios, respectively

carbon trade balance for region i and period $t$ for the delay and the 'all2010' scenarios, respectively

This decomposition (Fig. 5) reveals that the break-down of additional consumption losses caused by delayed climate policy varies between models and world regions. In all models the EU and the US are net importers and India and the rest of the non-Annex-I countries net exporters of allowances in all scenarios, with ambiguous outcomes for China and the rest of Annex-I. For WITCH differences in total consumption losses can to a large part be attributed to changes in domestic mitigation costs, while carbon trading plays a less important role. For IMACLIM$\mathrm{R}$ and ReMIND-R, however, the domestic mitigation cost effect and the carbon trade balance effect are of comparable magnitudes. For the EU and the US, both these models project that delaying action will result in significant extra spending on imports of allowances (caused by more imports and/or higher global carbon prices) and a widening deficit of the carbon trade balance accounts for most of the increase in total consumption losses.

The decomposition also confirms our earlier conjecture that delayed action can have ambiguous effects for net exporters of emission permits (especially India and the rest of non-Annex-I): on the one hand, domestic mitigation costs can increase due to lock-in of carbon-intensive energy infrastructure, on the other hand, due to a higher global carbon price, revenues from selling emission permits are likely to rise as well. This interaction of two effects helps to understand (a) why for IMACLIM-R and ReMIND-R delayed action lowers consumption losses for India (and the rest of non-Annex-I in some scenarios) which is a large exporter of emission permits, whereas for WITCH (where the carbon trade balance is less affected by a delay), 

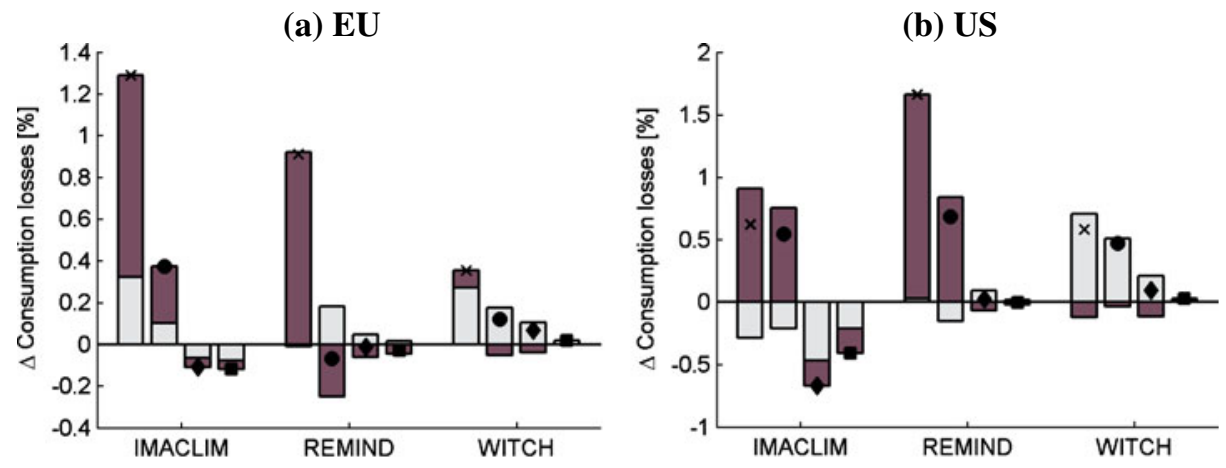

(c) RAI

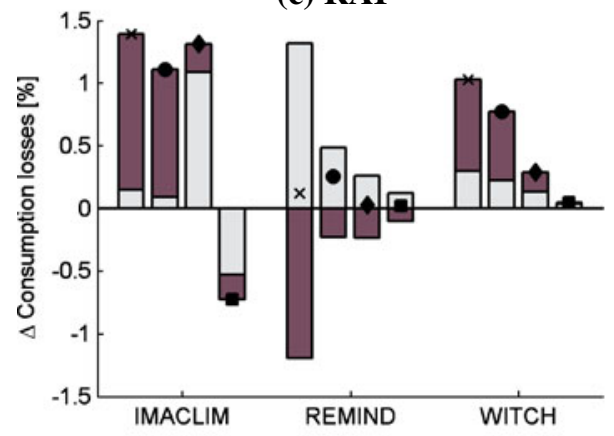

(d) $\mathrm{CHN}$

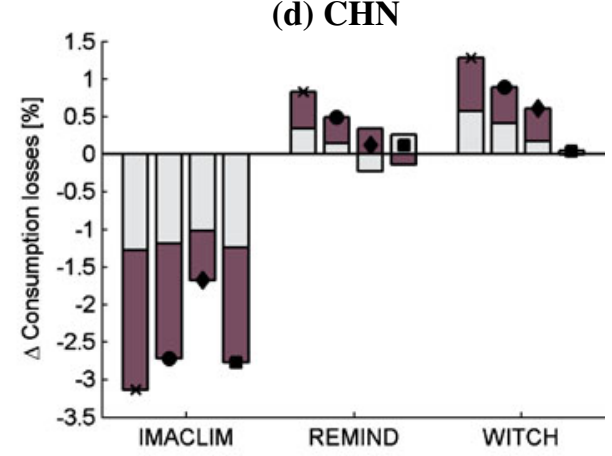

(e) IND

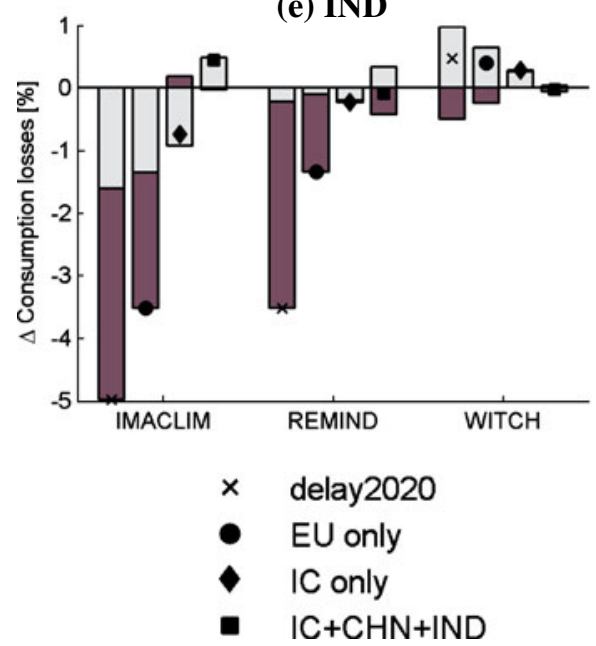

(f) RNAI

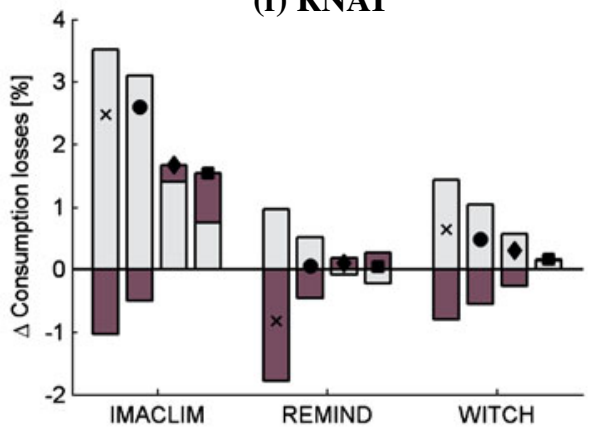

Fig. 5 a-f Differences in consumption losses (\%) between the delayed action scenarios and the 'all2010' scenario by world regions, disaggregated into changes in domestic mitigation costs and changes in the carbon trade balance. Please note different scales

additional revenues from exporting allowances are insufficient to offset increases in domestic mitigation costs, and (b) the ambiguous results for rest of non-Annex-I countries mentioned above. 
(a) pre-2020

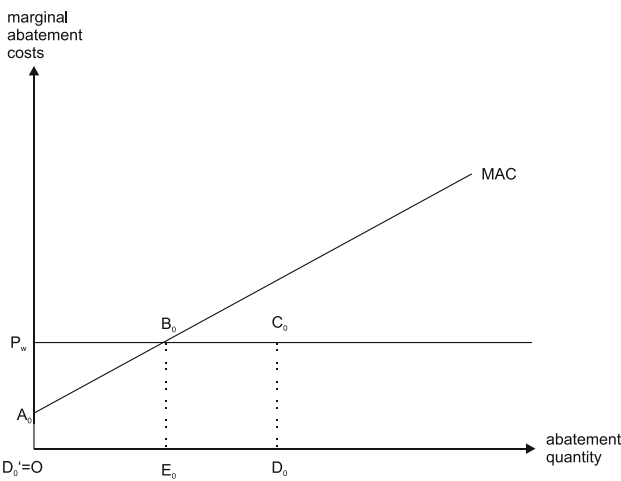

(b) post-2020

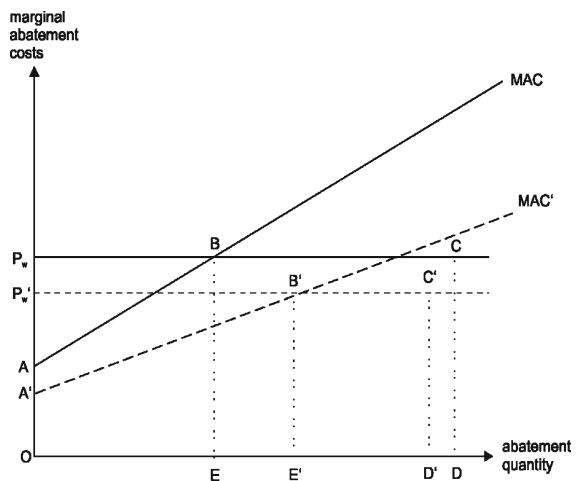

Fig. 6 Compared to delayed action, early action increases consumption losses in the pre-2020 period by the area $\mathrm{A}_{0} \mathrm{~B}_{0} \mathrm{C}_{0} \mathrm{D}_{0}(\mathbf{a})$, but decreases consumption losses in the post-2020 period from area $A B C D$ to $A^{\prime} B^{\prime} C^{\prime} D^{\prime}(\mathbf{b})$. Cost savings post-2020 are realized by reductions in (1) marginal abatement costs, (2) the total quantity of emissions to be abated over the period, and (3) the global carbon price

\subsection{Understanding the benefits of early action}

For some regions (including the EU and the US, if it acts within a coalition of all Annex-I countries) early action can result in lower consumption losses in the long run. Compared to the delay scenario, early action implies additional costs to abate carbon emissions prior to 2020. However, these find their correspondence in lower consumption losses in later periods due to three reasons (see Fig. 6): first, as lock-in in carbon intensive infrastructures can be avoided by early action, marginal abatement costs are lower after 2020 (shifting MAC to MAC'). Second, abatement in early periods reduces the mitigation burden in later periods (such that D shifts left to D'). However, this reduction in the individual mitigation burden is only a fraction of the abatement undertaken as an early mover prior to 2020, as the reduced commitment at later periods is divided between all countries according to the burden sharing rule (i.e. early effort has the character of a public good). Third, early action implies less global abatement in later periods, which in combination with less costly mitigation options in the early moving regions results in a lower global carbon price $\left(\mathrm{P}_{\mathrm{w}}\right.$ shifts down to $\left.\mathrm{P}_{\mathrm{w}}{ }^{\prime}\right)$ compared to the delayed action scenario. For net importers of emission permits all three effects contribute to lower consumption losses, which decrease from area $\mathrm{ABCD}$ to area $\mathrm{A}^{\prime} \mathrm{B}^{\prime} \mathrm{C}^{\prime} \mathrm{D}^{\prime} .{ }^{21}$ The level of domestic abatement (E and E', respectively) and imports of allowances (D-E and D'-E', respectively) can, however, go either way (the numerical results indicate that for our model setup early action consistently leads to more domestic abatement and reduces the import of emission permits).

To discern the impacts of the individual effects discussed above on changes of consumption losses between the early action 'all2010' and the respective delay

\footnotetext{
${ }^{21}$ For net exporters, the overall effect is ambiguous, as the first two effects have a positive welfare effect while the impacts of a lower global carbon price is negative.
} 
scenario, we separately apply the following (complete) decomposition to the pre2020 as well as the post-2020 period:

$$
\begin{aligned}
N P V\left(\Delta C L_{i}\right)= & N P V\left(\Delta D M C_{i}\right)-N P V\left(\Delta C T B_{i}\right) \\
= & N P V\left(\Delta D M C_{i}\right) \\
& +N P V\left\{p_{w}^{\text {early }} \cdot\left(D_{i}^{\text {early }}-E_{i}^{\text {early }}\right)-p_{w}^{\text {delay }} \cdot\left(D_{i}^{\text {delay }}-E_{i}^{\text {delay }}\right)\right\} \\
= & N P V\left(\Delta D M C_{i}\right)+N P V\left\{\Delta p_{w} \cdot\left(D_{i}^{\text {early }}-E_{i}^{\text {early }}\right)+p_{w}^{\text {early }} \cdot \Delta\left(D_{i}-E_{i}\right)\right. \\
& \left.+\Delta p_{w} \cdot \Delta\left(D_{i}-E_{i}\right)\right\} \\
= & \underbrace{N P V\left(\Delta D M C_{i}\right)}_{(1)}+\underbrace{N P V\left\{\Delta p_{w} \cdot\left[\left(D_{i}^{\text {early }}-E_{i}^{\text {early }}\right)-\frac{1}{2} \Delta\left(D_{i}-E_{i}\right)\right]\right\}}_{(2)} \\
& \underbrace{}_{(2)} \underbrace{N P V\left\{\left(D_{i}-E_{i}\right) \cdot\left[p_{w}^{\text {early }}-\frac{1}{2} \Delta p_{w}\right]\right\}}_{(2)}
\end{aligned}
$$

Here, $\Delta$ denotes the difference between the respective early action and the 'delay2020' scenario, $\mathrm{p}_{\mathrm{w}}$ the carbon price in those regions that undertake climate policy, D the commitment to reduce emissions, and E domestic abatement (i.e. the difference between BAU and actual domestic emissions). Consequently, (1) is the change in costs for abatement that is performed domestically, (2) the change in the carbon trade balance that can be attributed to the different carbon prices, and (3) the change in the carbon trade balance due to a different quantity of traded permits.

Figure 7 displays the differences in consumption losses between the respective early action scenario for the EU and the US (i.e. 'EU only' for the EU, and 'IC only'

(a) EU

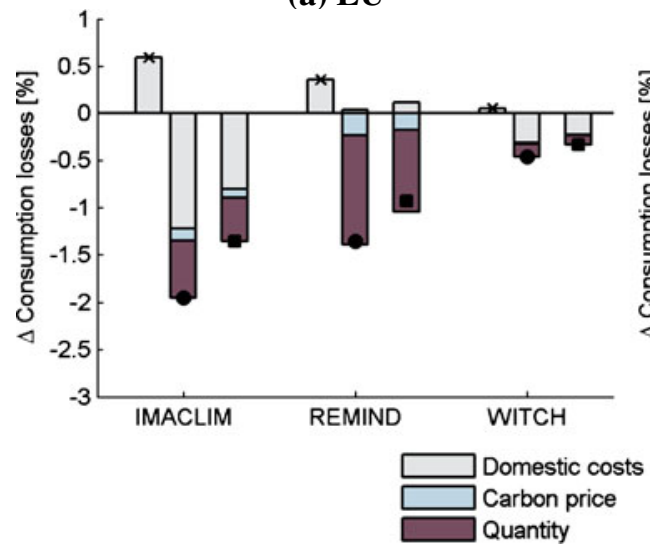

(b) US

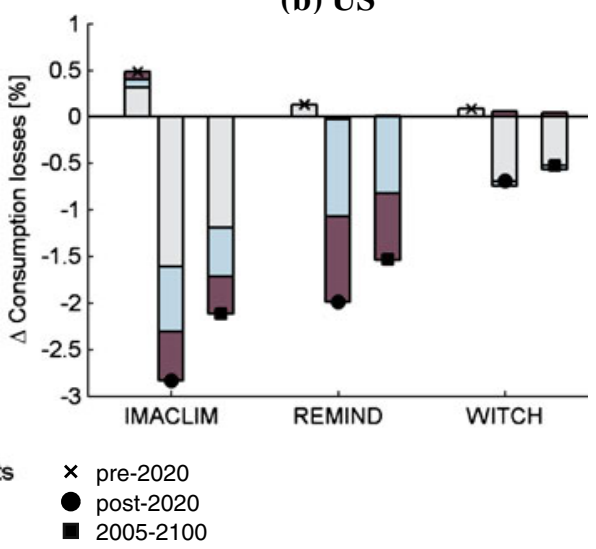

Fig. 7 Differences in consumption losses (\%) between early action scenarios (i.e. 'EU only' (a) for the EU and 'IC only' (b) for the US) and the 'delay2020' scenario for the periods pre-2020, post-2020, and 2005-2100. Cost differences are due to (1) changes in domestic mitigation costs, (2) different carbon prices, and (3) different quantities of traded permits 
for the US) and the 'delay2020' scenario. For all three models, the numerical results confirm that consumption losses are higher during the pre-2020 period in the early action scenario compared to the 'delay2020' scenario, but these expenses are more than compensated by cost savings in the years after 2020, such that early action turns out to be unambiguously beneficial over the period 2005-2100.

Due to high initial carbon prices necessary to shift the energy system away from its carbon-intensive trajectory, IMACLIM-R calculates a net present value of additional consumption losses of about $0.5 \%$ for the EU as well as the US in the period up to 2020 , but cost savings in the post-2020 period of about $2 \%$ of domestic consumption for the EU and $2.8 \%$ for the US. The later periods witness significantly lower domestic mitigation costs as well as decreased spending on imported emissions permits. For the EU, the lower volume of permit imports is the main effect responsible for a more favorable carbon trade balance, whilst for the US the effects of reduced quantities of imported permits and of lower carbon prices are of similar magnitude. For ReMIND, the additional costs (in terms of consumption) of early action are $0.3 \%$ for the EU and $0.2 \%$ for the US; for the EU (which as a single first mover has no possibility to engage in carbon trading) these costs of early action are exclusively and for the US to the largest part determined by the costs of domestic abatement. For both regions, post-2020 domestic mitigation costs in the early action scenario hardly differ from the 'delay2020' scenario, but the costs associated to imports of emissions permits decline by $1.4 \%$ for the EU and $2 \%$ for the US, indicating a shift in abatement strategies in which imports of emission permits are substituted by domestic abatement. As for IMACLIM-R, the quantity effect dominates for the EU, while for the US, the price effect is of comparable magnitude to the quantity effect (which seems quite intuitive, considering that early action by all Annex-I countries in the 'IC only' scenario can very likely be expected to decrease the price of carbon). In WITCH, where carbon trading plays a less important role, the costs and benefits of early action are mainly determined by differences in the costs of performing domestic abatement, and to a lesser extent by the amount of permits traded. For Europe, early action thus results in additional consumption losses of roughly $0.1 \%$ in the pre- 2020 period but decreases mitigation costs over the century by about $0.4 \%$; for the US the corresponding figures are $0.1 \%$ and $0.7 \%$, respectively.

The result that early action reduces consumption losses implies that the benefits of undergoing a smoother transition of the energy system and preventing lock-in effects exceed the costs related to the increased cumulative mitigation burden borne by early movers. As early action involves additional costs in the short run which are counterbalanced by cost savings in the long run, the discount rate (which is used to make costs that occur in different points in time comparable by converting them to net present values) is a crucial factor in determining whether early action turns out to be beneficial. Figure 8 shows differences between the respective early action scenario and the 'delay2020' scenario as a function of the discount rate for the periods 2005-2020 (light bars) and 2005-2100 (dark bars). It confirms the conclusion that early action entails considerably lower consumption losses for the EU and the US across a wide range of discount rates, ranging from 0 to $6 \%$. The total net benefits of early action (as a percentage of total consumption) can be regarded as a weighted average of avoided consumption losses in all periods, with higher discount rates putting less weight on cost savings that materialize in the farther future. Therefore, net benefits strictly decrease with a higher discount rate for WITCH, as for this model a large part of cost savings materialize in later periods. For IMACLIM-R and 
(a) EU, IMACLIM

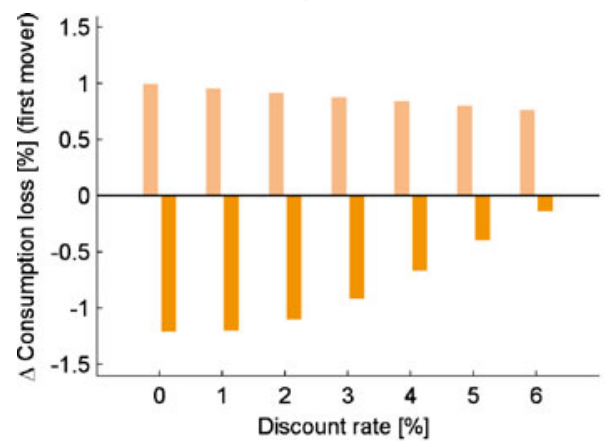

(b) EU, ReMIND

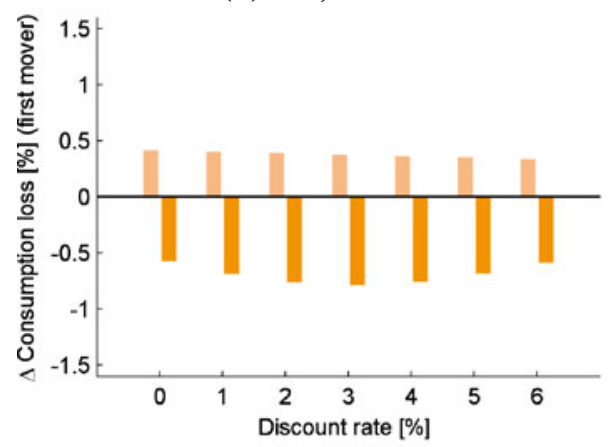

(c) EU, WITCH

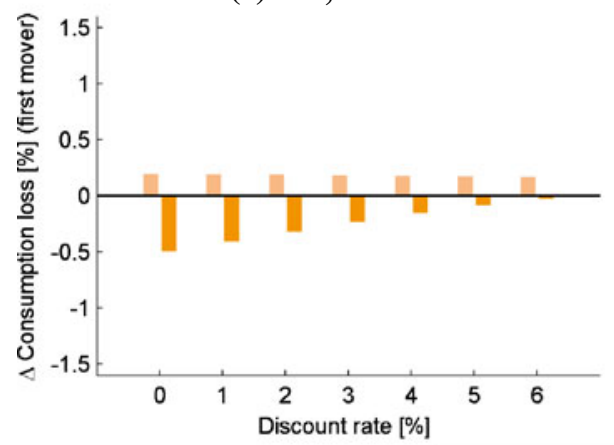

(d) US, IMACLIM

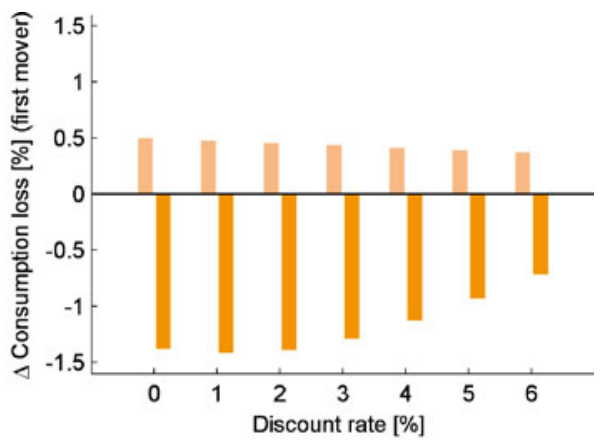

(e) US, ReMIND

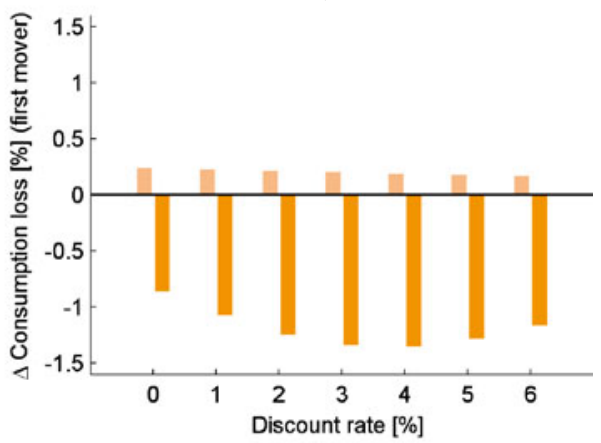

(f) US, WITCH

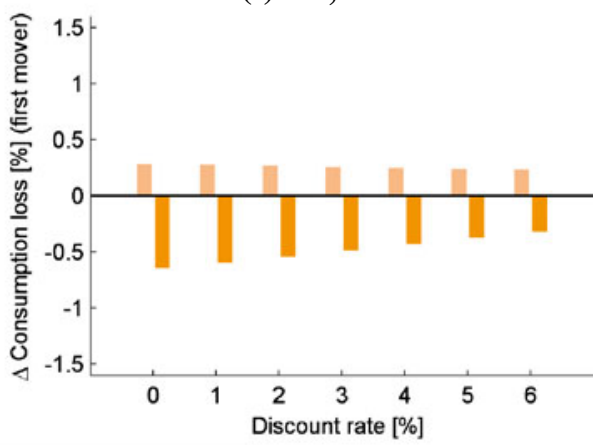

$2005 \cdot 2020$

$2005-2100$

Fig. 8 Differences in consumption losses (\%) between the respective early action scenario and the 'delay2020' scenario for the EU (a-c) and the US (d-f) in the short-term (2005-2020) and the longterm (2005-2100), applying discount rates ranging from 0 to $6 \%$

ReMIND-R, in turn, the largest cost savings take place in the first half of the century and cumulated net benefits only start decreasing with higher discount rates after the latter exceeds a certain level, resulting in a slightly hump-shaped relationship between the discount rate and the benefit of early action. 


\section{Concluding remarks}

This paper compares the results of three state-of-the-art climate-energy-economy models in order to analyze the economic implications of delaying climate policies in certain world regions. Our results indicate that globally, reducing 'where' and 'when' flexibility significantly raises the costs of achieving stabilization of atmospheric concentration at $450 \mathrm{ppm} \mathrm{CO}$-only: postponing a global agreement to 2020 raises global mitigation costs by at least about half and a delay to 2030 renders ambitious climate targets infeasible to achieve. With a larger number of key players participating in global mitigation efforts by 2010, global costs of stabilization decrease markedly and we find that the participation of the Annex-I countries as well as China and India is particularly relevant if large increases in mitigation costs are to be avoided.

For each region the effect of delayed action on mitigation costs is determined by the change in required emission reductions under the respective burden sharing scheme as well as differences in energy system developments and global carbon prices between scenarios. Assuming convergence of per-capita emissions in 2050, regions in which climate measures are implemented with a delay have to commit to smaller reductions of cumulative emission and hence bear a lower share of global mitigation costs. However, lock-in into carbon-intensive energy infrastructures can work in the opposite direction and increase mitigation costs by restricting the availability of low-cost options to abate carbon emissions. Reduced spatial and temporal flexibility raises the global carbon price and thus results in further consumption losses for regions which are net-importers of emission permits, but softens the adverse effects (and can even lead to net gains) for regions which are net-exporters of permits.

An important result is that regions with above average per-capita emissions, such as the EU and the US alongside the rest of Annex-I countries, can lower their mitigation costs by taking early action, even if mitigation efforts in the rest of the world experience a delay. For regions with low per-capita emissions which are net sellers of emission permits (such as India) we find that delayed mitigation efforts in other regions can be desirable, as they derive higher incomes from the sale of emission permits, stemming from the higher carbon prices implied by restricted spatial and temporal flexibility. Finally, decomposing the consumption losses for the EU and the US confirms the intuition that early action involves additional costs in early periods, but significant cost savings in later years. A sensitivity analysis shows that the finding that early action reduces consumption losses is robust over a wide range of discount rates.

It should be noted that the results crucially hinge on the assumption that (1) a universal climate agreement will eventually enter into force in 2020 and that (2) regions' relative shares in global emissions remain unchanged compared to the default $\mathrm{C} \& \mathrm{C}$ scenario. Yet, several authors have shown that if a global climate agreement is expected in the future, delaying action can influence strategic decisions and provide incentives to invest less in abatement technologies to increase their future bargaining position (Harstad 2009; Beccherle and Tirole 2010). We thus expect that developing a richer set of scenarios motivated by game-theoretic considerations will be one of the major challenges for future studies on delayed action.

We conclude that taking early action is crucial for stabilizing atmospheric GHG concentrations at $450 \mathrm{ppm} \mathrm{CO}_{2}$-only in a cost-efficient manner. The results of this paper suggest that if this stabilization target will be universally agreed upon in the 
future, early action on climate change constitutes a no-regret option for Annex-I countries, independent of the current state of climate policy in other parts of the world. If global action, however, is delayed for another decade, the above target can only be attained at significant additional costs, decreasing its political acceptability while increasing the likelihood that policy makers will favor a less ambitious climate agreement instead, including the related adverse environmental impacts.

Acknowledgements The authors would like to thank the three anonymous reviewers for their helpful comments, which improved this paper substantially. The RECIPE project was funded by Allianz and WWF Europe.

\section{References}

Beccherle J, Tirole J (2010) Regional initiatives and the cost of delaying binding climate change agreements, mimeo

Bosetti V, Carraro C, Galeotti M, Massetti E, Tavoni M (2006) A world induced technical change hybrid model. Energy J 27(Special Issue 2):13-38

Bosetti V, Carraro C, Galeotti M, Massetti E, Tavoni M (2007) The WITCH model: structure, baseline and solution. FEEM Working Paper N. 10.2007, Milan

Bosetti V, Carraro C, Sgobbi A, Tavoni M (2009) Delayed action and uncertain targets. How much will climate policy cost? Clim Change 96:299-312

Clarke L, Edmonds J, Krey V, Richels R, Rose S, Tavoni M (2009) International climate policy architectures: overview of the EMF 22 International Scenarios. Energy Econ 31(Supplement 2):S64-S81

Davis SJ, Caldeira K, Matthews HD (2010) Future CO2 emissions and climate change from existing energy infrastructure. Science 10(5997):1330-1333

Edenhofer O, Carraro C, Koehler J, Grubb M (eds) (2006) Endogenous technological change and the economics of atmospheric stabilisation. A special issue of the energy journal, vol 27

Edmonds J, Clarke L, Lurz J, Wise M (2008) Stabilizing $\mathrm{CO}_{2}$ concentrations with incomplete international cooperation. Climate Policy 8:355-376

Fisher BS, Nakicenovic N, Alfsen K, Corfee Morlot J, de la Chesnaye F, Hourcade J-C, Jiang K, Kainuma M, La Rovere E, Matysek A, Rana A, Riahi K, Richels R, Rose S, van Vuuren D, Warren R (2007) Issues related to mitigation in the long term context. In: Metz B, Davidson OR, Bosch PR, Dave R, Meyer LA (eds) Climate change 2007: mitigation. Contribution of Working Group III to the Fourth Assessment Report of the Inter-governmental Panel on Climate Change. Cambridge University Press, Cambridge

Flachsland C, Marschinski R, Edenhofer O (2009) Global trading versus linking. Architectures for international emissions trading. Energy Policy 37:1637-1647

Ha-Duong M, Grubb MJ, Hourcade J-C (1997) Influence of socioeconomic inertia and uncertainty on optimal CO2-emission abatement. Nature 390(6657):270-273

Harstad B (2009) The dynamics of climate agreements. Harvard Project on International Climate Agreements Discussion Paper 09-28

Jakob M, Bosetti V, Waisman H, De Cian E, Steckel J, Leimbach M, Baumstark L (2009a) The RECIPE reference scenarios. RECIPE Backgound Paper. http://www.pik-potsdam.de/members/ jakob/publications/recipe-baseline-scenarios

Jakob M, Waisman H, Bosetti V, De Cian E, Leimbach M, Baumstark L, Luderer G (2009b) Description of the RECIPE models. RECIPE Backgound Paper. http://www.pik-potsdam.de/ members/jakob/publications/recipe-model-descriptions

Keppo I, Rao S (2007) International climate regimes: effects of delayed participation. Technol Forecast Soc Change 74(7):962-979

Knopf B, Edenhofer O, Flachsland C, Kok MTJ, Lotze-Campen H, Luderer G, Popp A, van Vuuren DP (2010) Managing the low-carbon transition - from model results to policies. Energ J 31(Special Issue 1):223-245

Leimbach M, Bauer N, Baumstark L, Edenhofer O (2009) Mitigation costs in a globalized world: climate policy analysis with ReMIND-R. Environ Model Assess 15:155-173 
Luderer G, Bosetti V, Jakob M, Leimbach M, Steckel J, Waisman H, Edenhofer O (2011a) The economics of decarbonizing the energy system - results and insights from the RECIPE model intercomparison. Clim Change. doi:10.1007/s10584-011-0105-x

Luderer G, DeCian E, Hourcade J-Ch, Leimbach M, Edenhofer O (2011b) The regional distribution of mitigation costs-a tale of scarcity rents. Clim Change (this issue)

Meinhausen M, Meinshausen N, Hare W, Raper S, Frieler K, Knutti R, Frame D, Allen M (2009) Greenhouse-gas emission targets for limiting global warming to $2^{\circ} \mathrm{C}$. Nature $458: 1158-1163$

Meyer A (2004) Briefing: contraction and convergence. Engineering Sustainability 157(Issue 4):189192

Mignone B, Socolow R, Sarmiento J, Oppenheimer M (2008) Atmospheric stabilization and the timing of carbon mitigation. Clim Change 88(3):251-265

Nordhaus WD (1992) An optimal transition path for controlling greenhouse gases. Science 258:13151319

Nordhaus WD, Yang Z (1996) A regional dynamic general-equilibrium model of alternative climatechange strategies. Am Econ Rev 86(4):741-765

Richels R, Rutherford T, Blanford G, Clarke L (2008) Managing the transition to climate stabilization. Climate Policy 7(5):409-428

Sassi O, Crassous R, Hourcade J-C, Gitz V, Waisman H, Guivarch C (2010) Imaclim-R: a modelling framework to simulate sustainable development pathways. Int J Global Environmental Issues 10(1/2):5-24

Stern N (2006) The economics of climate change. The Stern Review. Cambridge University Press, New York

UNFCCC (2009) Decision -/CP.15. Available online at http://unfccc.int/files/meetings/cop_15/ application/pdf/cop15_cph_auv.pdf

van Vliet J, den Elzen MGJ, van Vuuren DP (2009) Meeting radiative forcing targets under delayed participation. Energy Econ 31:152-162

Wigley T, Richels R, Edmonds J (1996) Economic and environmental choices in the stabilization of atmospheric CO2 concentrations. Nature 379(6562):240-243 